Article

\title{
Sustainable Consumer Tax Evasion Theory under Information Inattention
}

\author{
Bodo Herzog 1,2,3 (i)
}

Abstract: This article studies the renewed interest surrounding sustainable public finance and the topic of tax evasion as well as the new theory of information inattention. Extending a model of tax evasion with the notion of inattention reveals novel findings about policy instruments that can be used to mitigate tax evasion. We show that the attention parameters regarding tax rates, financial penalty schemes and income levels are as important as the level of the detection probability and the financial penalty incurred. Thus, our theory recommends the enhancement of sustainability in public policy, particularly in tax policy. Consequently, the paper contributes both to the academic and public policy debate.

Keywords: tax evasion; sustainable policy; behavioral inattention

JEL Classification: H26; D81; H21; D91; H71

\section{Introduction}

Tax evasion is a recurring theme in public policy. Recent international tax scandals, such as the Panama Papers in 2016 and the Paradise Papers in 2017, have highlighted the ongoing perpetration of tax avoidance and tax evasion. Furthermore, governments fear unsustainable public debts due to lower tax revenues and higher spending in the aftermath of the SARS-CoV-2 pandemic. As a matter of fact, in a world of financial globalization, the notions of fiscal prudence, fiscal competition, tax avoidance and tax evasion have become commonplace. Thus, the topic in our paper contributes to a lasting challenge in public policy.

There is a long-standing body of theoretical and empirical literature on sustainable public economics [1]. Seminal empirical studies have demonstrated that the sustainability of public finances can be measured by regressing the present value of primary deficits to the debt stock over time [2-4]. Recent articles have studied the sustainability of public debts during the SARS-CoV-2 pandemic $[5,6]$. This article relates to this literature; however, it newly contributes by focusing on sustainable tax revenues and the well-known challenge of tax evasion. We incorporate behavioral inattention into a tax evasion model. Our approach reveals novel policy conclusions, such as a new link between tax evasion and inattention, which potentially endangers the future sustainability of public finances.

Since the 1970s, there has been an established academic theory regarding optimal taxation [7]. However, this theory has behavioral flaws, as recently demonstrated by Farhi and Gabaix [8]. In addition, there is little progress in the mitigation of tax evasion, particularly in an interconnected world. One reason for this is the international competition that forces especially small countries to create attractive tax havens. A second driver behind this lack of mitigation is the increasingly complex tax rules within and across countries, which creates regulatory arbitrage. Furthermore, and even more fundamentally, there is a third reason: information inattention. 
The tax literature implicitly assumes that firms and consumers understand tax rules and report their taxable incomes or profits honestly. This assumption is disproven when confronted with reality. Indeed, firms and consumers do not fully grasp tax rules and are deterred from knowing the true effective tax rate or penalties due to incomplete information and the complexity of tax exemption rules [9]. The US General Accountability Office [10] argued that complexity contributes to the "tax gap" between what tax is owed and what is paid. Furthermore, this is aggravated by the finding of behavioral notions, such as inattention, subjective biases or the costs of complexity in usual taxpayer decision processes [11]. These issues are neither studied nor discussed in a unified theory of tax evasion under information inattention. Thus, for the first time, this article analyzes tax evasion under information inattention.

We employ the idea of information inattention and integrate this feature in a standard Allingham and Sandmo [12] framework. In this model, we study the sustainability of policy parameters affecting tax evasion such as the tax rate, the detection probability, the penalties imposed for evaded taxes and-most importantly-the effect of inattention on those policy instruments. This paper uniquely connects both academic and public policy fields of literature in order to foster a better understanding of why and where the theory of tax evasion fails. Moreover, this model reveals policy conclusions regarding the design of sustainable tax schemes in order to mitigate tax evasion. We study the role of inattention both from the perspective of the taxpayers and the tax authority. To answer the question of what, if any, public policy can be used to prevent tax evasion, we discover a new tax-inattention trade-off.

Tax theory delineates three related concepts: first, tax avoidance, as a legal activity undertaken to reduce taxes; second, the issue of tax compliance and more general tax morality [13], where taxpayers have an obligation to play by the rules but they are ambiguous regarding those rules [14]; and, third, tax evasion, which is an illegal action with the purpose of underpaying taxes [15]; in this scenario, if the tax authority were to have all of the information, the taxpayer would have to pay more taxes than reported [16].

Recently, Sims [17] laid the foundation for the theory of rational inattention. In general, this theory demonstrates that inattention is the major source of the slow adjustment of prices and wages in macroeconomics. Recently, Gabaix [18] established a unifying theory in order to study both rational and behavioral inattention. Among other factors, the new theory was motivated by an example in taxation: suppose that the true effective tax rate $t$ is unknown by agents due to the complexity of the tax rules. Under those circumstances, the taxpayer would approximate the effective tax rate by the so-called perceived tax rate $t_{s}=m \times t$, where $m \in(0 ; 1]$ measures the (in)attention. Thus, under full attention $m=1$, the perceived tax rate would be equal to the effective tax rate. However, under inattention $m \approx 0$, the perceived tax rate would be lower. The same effect occurs at the tax authority. Only under complete information would the tax authority know the true income of the agent. In reality, however, tax authorities face both incomplete information and inattentive taxpayers. As a result, the behavioral biases are two-sided, since they occur both on the part of the tax authorities and of the taxpayers.

Our analysis makes several contributions. First of all, we uncover novel policy conclusions regarding the level of tax evasion contingent to the tax rate, the punishment scheme and the probability of detection. We find that an agent's tax evasion is critically reliant on the degree of (in)attention. Second, there is a new tax trade-off between the tax and penalty system under information inattention. This trade-off causes tax evasion, in general, despite high detection probabilities or fines. The reasons for inattention are broad, but they might be caused by overly complex tax or penalty schemes. Third, we find that, the higher the attention to the penalty scheme and tax rate, the lower the rate of tax evasion. Fourth, the existence of inattention mitigates the well-known effect of a high penalty or detection probability on the declared income. Although our paper focuses on sustainable consumer tax evasion theory, there is a need for future research, particularly regarding inattention and the role of tax evasion by firms. 
The structure of the paper is as follows: Section 2 covers the literature. Section 3 briefly introduces the model of tax evasion and explores the idea of information inattention. Section 4 examines the unified model in order to derive optimal conditions. In Section 5 , we show numerical implications. Finally, Section 6 concludes the paper.

\section{Literature Review}

This article relates to at least two strands of literature. First, there is a long list of theoretical and empirical literature on public debt sustainability, tax avoidance and tax evasion $[1,4,14]$. The beginning of the empirical literature has firstly estimated the extent of tax evasion within the economy. One of the first articles in this field studied the Italian General Sales Tax [19]. He estimated that evasion was equal to almost 52 per cent. Similarly, Gutmann [20] studied the degree of unobserved economic activity and found that approximately 10 per cent of the legal activity is unreported. Since then, scholars have estimated the range of tax evasion from 5 to 15 per cent of Gross National Product (GNP). The empirical findings confirm the existence of some degree of tax evasion in almost all countries and jurisdictions [21-23]. A recent empirical study related to our topic is by Chetty et al. [24]. In general, there are empirical studies by Blackburn et al. [25], Reimers [26], Cobham and Jansky [27], and Alstadsæter et al. [16].

Indeed, Allingham and Sandmo [12] already recognized that the model does not capture all reasons for tax compliance, stating: "This is a very simple theory, and it may perhaps be criticized for giving too little attention to nonpecuniary factors ( ... )." The review by Luttmer and Singhal [13] on tax morale discusses some evidence, suggesting that tax compliance appears to be slightly higher than in the Allingham-Sandmo framework. Our model intends to include inattention to the Yitzhaki [28] approach in order to further study the gap between theory and evidence. Similar to our approach is a work by Srinivasan [29], Clotfelter [15], Snow and Warren [30] and Lawsky [31]. The latter represent models of tax compliance where the taxpayers have ambiguity about the detection probability. We do not follow this literature because probabilities are subjective and ambiguous from a taxpayer's vantage point. Indeed, there is little evidence that detection probabilities enhance the tax moral [13].

The second field of literature related to our paper is the field of information inattention. Naturally, tax evasion is salient on the issue of behavioural notions. The origin of this literature is akin to the psychology of anchoring [32-35]. Sims [17] discovered that the gap between economic data and theory can be accounted for by the idea of rational inattention. In fact, several papers in macroeconomic literature have studied the impact of inattention on consumer choice [36,37]. Similarly, there are papers in monetary policy by Woodford [38] as well as in economic theory by Lorenzoni [39], Mackowiak and Wiederholt [40,41] and Angeletos and La'O [42].

Over the last few years, the concept of behavioral inattention has been developed [43-45]. Recently, Farhi and Gabaix [8] and Gabaix [18] proposed a unifying approach. Our paper follows this path and applies it to the literature on tax evasion. To our knowledge, there is only a single quantitative study in this field by Allcott et al. [46]. Consequently, this article contributes to the new subfield of inattention and tax evasion.

\section{Model}

In this section, we describe a benchmark model of tax evasion following Yitzhaki [28]. Suppose an agent receives an exogenous income $M$, which is known to the agent but not to the government (i.e., tax authority). Furthermore, assume that the agent declares an income $X$ to the tax authority, which is taxed at a constant rate $t \in(0,1]$. The probability $p$ denotes the likelihood that the tax authority detects tax evasion, i.e., $X \leq M$, in which case, it punishes the agent with a fine $F>1$. Given these assumptions, the agent aims 
to declare income $X$ so as to maximize a standard von Neumann-Morgenstern expected utility function of the form:

$$
\max _{X} \mathbb{E}[U(X)]=(1-p) U(M-t X)+p U(M-t X-F t[M-X]),
$$

where the derivatives of the concave utility function follow the standard assumptions: $U^{\prime}(\xi)>0$ and $U^{\prime \prime}(\xi)<0$ for all $\xi>0$.

Inattention about the tax policy is put forward by Gabaix [18]: suppose the price of a good is denoted by $\bar{p}$ and the tax is of $t$. Thus, the full price is $q=\bar{p}+t$. In general, however, a consumer is paying only partial attention to the tax rate, so the perceived tax is $t_{s}=m t+(1-m) t_{d}$, where $t_{d}$ is a subjective default tax rate. Subsequently, the perceived price is of $q_{s}=\bar{p}+\left[m t+(1-m) t_{d}\right]$, where $m \in[0,1]$ measures (in)attention. The standard microeconomic literature defines a price always under full attention or $m=1$. Nonetheless, theoretical and empirical studies demonstrate that market prices deviate due to behavioral biases such as inattention [18]. Thus, our model considers the notion of inattention and studies the sustainable level of policy parameters in relation to tax evasion. Consequently, under inattention, the market price or tax rate is perceived either higher or lower, which biases consumer choice and the sustainable development of the economy.

Next, we extend the tax evasion model with this notion of behavioral inattention. First, agents perceive both a tax rate $t_{s}$, a fine $F_{s}$ and a probability $p_{s}$, equivalently to Gabaix [18], by

$$
\begin{aligned}
& t_{s}=m_{t} \times t+\left(1-m_{t}\right) \times t_{d}, \\
& F_{s}=m_{F} \times F+\left(1-m_{F}\right) \times F_{d}, \\
& p_{s}=m_{p} \times p+\left(1-m_{p}\right) \times p_{d},
\end{aligned}
$$

where $m_{t}, m_{F}$ and $m_{p}$ denote measures of (in)attention respectively. The default tax rate $t_{d}$, fine $F_{d}$, and probability $p_{d}$ are subjective ad hoc estimates. In addition, we assume $F>F_{d}>1$, where $F_{d}$ is the individual's default fine, which is perceived lower than the true fine $F$ due to infrequent tax audits and little exposure to fines. On the contrary, the tax rate is perceived either $t>t_{d}$ or $t<t_{d}$ and similarly for probabilities $p$. Attention parameters are defined by $m_{i} \in[0,1]$ for $i=t, F, p$. Full attention implies $m_{i}=1$. Behavioral inattention leads to lower perceptions; $m_{i} \approx 0$. The model works similarly with a random shock parameter, such as assuming a perceived tax rate of $t_{s}=m_{t} \times t+\epsilon$. The random variable $\epsilon$ is defined by a normal distribution $\mathcal{N}\left(0, \sigma_{\epsilon}^{2}\right)$ and does not affect our findings due to $\mathbb{E}[\epsilon]=0$ in the expected utility function.

Second, we consider inattention about aggregate income $M$. This is a common issue if household income comes from different sources such as work by the wife and husband, secondary employments, renting, investing, leaseholds or profits. The perceived income is defined by $M_{s}=m_{M} M+\left(1-m_{M}\right) \bar{M}$, where $m_{M}$ measures the attention and $\bar{M}$ denotes the expected income with the assumption $M>\bar{M}+1$.

Consequently, we obtain the von Neumann-Morgenstern expected utility function as

$$
\max _{X} \mathbb{E}[U(X)]=\left(1-p_{s}\right) U\left(M_{s}-t_{s} X\right)+p_{s} U\left(M_{s}-t_{s} X-F_{s} t_{s}\left[M_{s}-X\right]\right),
$$

where $M_{s}=m_{M} M+\left(1-m_{M}\right) \bar{M}$ and $t_{s}, F_{s}$ and $p_{s}$ are defined in Equations (2)-(4). In order to simplify the computation, we define the first input of the utility function as $Y:=M_{s}-t_{s} X$ and the second as $Z:=M_{s}-t_{s} X-F_{s} t_{s}\left[M_{s}-X\right]$.

\section{Results and Discussion}

Next, we analyze the choice problem of optimal tax evasion with information inattention in our unified model. The optimal level for the declared income $X$ is determined by the first-order derivative of Equation (5): 


$$
\frac{d \mathbb{E}[U(X)]}{d X}=0 \Longleftrightarrow-\left(1-p_{s}\right) U^{\prime}(Y)+p_{s} U^{\prime}(Z)\left[-1+F_{s}\right]=0 .
$$

In order to guarantee the maximum, we compute the second derivative, as follows:

$$
\frac{d^{2} \mathbb{E}[U(X)]}{d X^{2}}=: S \Longleftrightarrow\left(1-p_{S}\right) U^{\prime \prime}(Y)+p_{S} U^{\prime \prime}(Z)\left[-1+F_{S}\right]^{2}=: S .
$$

We find that the second derivative, defined by $S$, is negative due to $U^{\prime \prime}(Y)<0$ and $U^{\prime \prime}(Z)<0$. If the declared income equals the perceived income, i.e., $X=M_{s}$, we obtain benefits from evading taxes. Indeed, the necessary first-order condition to evade taxes is given by

$$
-\left(1-p_{S}\right)+p_{S}\left[-1+F_{S}\right]=-1+p_{S} F_{S} \leq 0 \quad \Longleftrightarrow \quad p_{S} F_{S} \leq 1
$$

Hence, we need a balance between the perceived fine $F_{S}>1$ and the perceived detection probability of tax evasion $p_{s}<1$ in order to obtain $p_{s} F_{S} \leq 1$. Consequently, the attention parameters $m_{F}$ and $m_{p}$ as well as $p$ and $F$ play a major role.

For the first time, we reveal a new trade-off between the agent's information inattention and the fine scheme. This policy trade-off is a major insight concerning the mitigation of tax evasion under information inattention. Under inattention, both $m_{F}$ and $m_{p}$ are zero and we obtain $p_{d} F_{d} \leq 1$. However, the last condition implies that tax evasion is singularly determined by the (subjective) default parameters $p_{d}, F_{d}$ and neither by the true fine scheme $F$ or detection probability $p$. This creates a new driver for the existence of tax evasion-even if the true detection probability, $p$, and the fine, $F$, are high. This finding is summarized in the first proposition.

Proposition 1. The behavioral tax trade-off is obtained by $p_{s} F_{S} \leq 1$. However, under information inattention $\left(m_{F} \rightarrow 0\right.$ and $\left.m_{p} \rightarrow 0\right)$, we obtain $p_{d} F_{d} \leq 1$ with incentives to evade taxes unrelated to the official level of fine $F$ and detection probability $p$.

The proof follows from Equation (8) together with (3) and (4). Thus, the origin of tax evasion is not merely a function of the true fine and/or detection probability.

Next, we study the comparative statics of the model parameters $p_{s}, F_{s}, t_{s}, M_{s}, p, F, t, M$ as well as the attention parameters $m_{p}, m_{F}, m_{M}, m_{t}$ in relationship to the level of declared income $X$.

Proposition 2. The detection probability of tax evasion is positively related to the level of declared income, such that

$$
\begin{aligned}
& \frac{d X}{d p_{s}}=-\frac{U^{\prime}(Y)+U^{\prime}(Z)\left[F_{s}-1\right]}{S}>0 \\
& \frac{d X}{d p}=-m_{p} \frac{U^{\prime}(Y)+U^{\prime}(Z)\left[F_{S}-1\right]}{S} \geq 0 .
\end{aligned}
$$

The proof is in Appendix A. This finding newly demonstrates that an increasing detection probability of tax evasion is not sufficient to avoid tax evasion. The relationship is only greater than zero, thereby reducing tax evasion, if the agent has a sufficiently high attention directed to the detection probability, defined by $m_{p}^{*}$. Additionally, the empirical literature has found a low mean attention to taxes generally between $m=0.06$ and $m=0.35$ [18]. Thus far, the unquestioned positive relationship from the existing tax evasion literature might not hold universally. This finding is corroborated by the effect of the attention parameter $m_{p}$ : 
Proposition 3. The attention to the detection probability is either positively or negatively related to the level of declared income, such that

$$
\frac{d X}{d m_{p}}=-\left(p-p_{d}\right) \frac{U^{\prime}(Y)-U^{\prime}(Z)\left[F_{s}-1\right]}{S}\left(\begin{array}{c}
>0 \\
<0
\end{array}\right) \text { if }\left(\begin{array}{c}
p>p_{d} \\
p<p_{d}
\end{array}\right) .
$$

Proposition 3 follows empirical evidence if individuals have incomplete information about tax audits or penalties [9]. Growing attention only mitigates tax evasion if the individual underestimates the true detection probability, i.e., $p>p_{d}$. The notion that individuals may overweight small probabilities is predicated by prospect theory [30]. Consequently, both a high fine and detection probability are not sufficient in order to mitigate tax evasion according to our theory. The next proposition demonstrates a similar point for the fine scheme.

Proposition 4. The attention to the fine scheme is positively related to the level of declared income, such that

$$
\frac{d X}{d m_{F}}=-\left(F-F_{d}\right) \frac{p U^{\prime}(Z)-U^{\prime \prime}(Z) p t_{S}\left(M_{S}-X\right)\left[F_{S}-1\right]}{S}>0 .
$$

The proof is in Appendix B. Indeed, alleviating tax evasion requires some attention to the fine scheme $m_{F}$ too. Next, we study the impact of the level of the fine $F$ with respect to the declared income $X$.

Proposition 5. The level of the fine is positively related to the level of declared income, such that

$$
\begin{aligned}
\frac{d X}{d F} & =-m_{F} \frac{p_{s} U^{\prime}(Z)-U^{\prime \prime}(Z) p_{s} t_{S}\left(M_{S}-X\right)\left[F_{S}-1\right]}{S}>0, \\
\frac{d X}{d F_{d}} & =-\left(1-m_{F}\right) \frac{p_{s} U^{\prime}(Z)-U^{\prime \prime}(Z) p_{s} t_{S}\left(M_{S}-X\right)\left[F_{S}-1\right]}{S}>0 .
\end{aligned}
$$

As expected, an increasing fine leads to a reduction in the level of tax evasion (i.e., an increase in declared income $X$ ); however, it is conditional upon the attention to the fine $m_{F}$ (proof in Appendix B). This uncovers the policy conclusion similarly to the US General Accountability Office report [10]: any fine scheme must be sufficiently transparent [or simple] so as to close the 'tax gap'. A more transparent tax scheme might support the agents' attention to the policy parameters. Therefore, both punishment variables-the detection probability and fine-are critically dependent on the agent's attention.

The next variable to consider is the tax rate upon declared income.

Proposition 6. The tax rate is positively related to the level of declared income, such that

$$
\begin{aligned}
& \frac{d X}{d t}=-m_{t} \frac{\left(1-p_{s}\right) U^{\prime}(Y)\left[X\left(R_{A}(Z)-R_{A}(Y)\right)+F_{s}\left[M_{s}-X\right] R_{A}(Z)\right]}{S}>0 \\
& \frac{d X}{d t_{d}}=-\left(1-m_{t}\right) \frac{\left(1-p_{s}\right) U^{\prime}(Y)\left[X\left(R_{A}(Z)-R_{A}(Y)\right)+F_{s}\left[M_{S}-X\right] R_{A}(Z)\right]}{S}>0 .
\end{aligned}
$$

The proof is in Appendix $C$. Note that $R_{A}$ is the absolute risk aversion, defined by $R_{A}(Y)=-U^{\prime \prime}(Y) / U^{\prime}(Y)>0$, and we assume $R_{A}(Z)-R_{A}(Y)>0$ as in the literature. The last condition implies that absolute risk aversion decreases as income increases, which is valid intuitively. With this standard assumption, our result is the same as in the existing literature, and it reveals that a higher tax rate increases declared income and thus mitigates tax evasion. However, the size of the effect is newly contingent on the attention parameter to the tax rate, $m_{t}$. Behavioral inattention mitigates this effect, while under full attention the standard result from the literature is obtained. Similarly, we find for the tax attention parameter: 
Proposition 7. The attention to the tax rate is either positively or negatively related to the level of declared income, such that

$$
\frac{d X}{d m_{t}}=-\left(t-t_{d}\right) \frac{\left(1-p_{s}\right) U^{\prime}(Y)\left[X\left(R_{A}(Z)-R_{A}(Y)\right)+F_{S}\left[M_{S}-X\right] R_{A}(Z)\right]}{S}\left(\begin{array}{c}
>0 \\
<0
\end{array}\right) \text { if }\left(\begin{array}{c}
t>t_{d} \\
t<t_{d}
\end{array}\right) .
$$

Of course, the last proposition is intuitive and in-line with our expectation. An increasing attention about the true tax rate reduces the incentive to evade taxes. There is empirical evidence that a fair and transparent tax regime increases tax compliance through the channel of peer pressure, moral suasion and the perceived shared responsibility to the community [47]. Finally, we analyze the impact of the true income $M$ on $X$ as well as the attention of the true income $m_{M}$.

Proposition 8. The true income is positively related to the level of declared income, such that

$$
\frac{d X}{d M}=m_{M} \frac{\left[R_{A}(Z)-R_{A}(Y)\right]-t_{s} F_{S} R_{A}(Z)}{\left[R_{A}(Z)-R_{A}(Y)\right]-F_{S} R_{A}(Z)}>1 .
$$

The details of the proof are in Appendix D. Intuitively, the declared income rises at a faster rate than the true income, implying that tax evasion declines along with income. This result, however, is again contingent on the attention of the true income $m_{M}$. In case of inattention, this effect is almost negligible, such as $m_{M} \rightarrow 0$ and so $d X / d M \rightarrow 0$. Of even higher interest is the relationship with respect to $m_{M}$ :

Proposition 9. The attention on true income relates to the level of declared income, such that

$$
\frac{d X}{d m_{M}}=(M-\bar{M}) \frac{\left[R_{A}(Z)-R_{A}(Y)\right]-t_{s} F_{S} R_{A}(Z)}{\left[R_{A}(Z)-R_{A}(Y)\right]-F_{S} R_{A}(Z)}>1 .
$$

The proof is in Appendix E. The proposition shows that the declared income increases faster than the attention on the true income. Thus, the higher the agents' attention about the income, the higher the declared income and thus the lower tax evasion. This finding reveals the importance of a comprehensive income tax card including at best all components of household income.

Finally, we study the problem of tax evasion from the tax authority's perspective. The perceived tax revenues are defined as $R=t X+p_{s} F_{s} t\left(M_{s}-X\right)$. The first term denotes tax revenues from the declared income. The second term captures tax revenues in case of punishment under tax evasion. It consists of the perceived detection probability and fine because of almost random audits and subsequently fines. Thus, public tax revenues are newly contingent on the inattention parameters. Next, we compute the first-derivatives with respect to the major policy variables:

Proposition 10. Tax revenues $R$ behave according to

$$
\begin{array}{rlrlrl}
\frac{d R}{d p_{s}}>0 & \frac{d R}{d F_{s}}>0 & \frac{d R}{d t}>0 & \frac{d R}{d M_{s}}>0 \\
\frac{d R}{d m_{F}}>0 & \frac{d R}{d m_{t}}>0 & \frac{d R}{d m_{M}}>0 .
\end{array}
$$

The proofs are in Appendix F. As expected, a higher detection probability, a higher fine or attention on the fine, a higher tax rate or attention on the tax or a higher income or attention on income, increase the public tax revenues. This is intuitive, but it demonstrates that the attention parameters are a major determinant of public tax revenues too. In fact, under inattention, the positive links are virtually negligible. 


\section{Numerical Discussion}

The numerical computation of the conditions under information inattention is revealing interesting results with regard to the minimum detection probability as well as punishment level.

The attention parameter to the tax rate is in a range of $m=0.06$ to $m=0.35$ as given in the literature [18]. Furthermore, we suppose the same range for $m_{F}$ on fine schemes because there is a lack in existing empirical research. Instinctively, it should be quite a bit lower because of the complexity and conditionalities of modern fine structures. Hence, the proposed attention parameters are rather upper bounds. Furthermore, we suppose a range of detection probabilities; starting at 10 percent with steps of 10 percentage points up to 100 percent. In addition, we assume an income tax rate of 30 percent.

Naturally, the simulation exercise is stylized, yet it uncovers thought-provoking effects on tax evasion under the phenomena of inattention. First, we start with the condition $p_{s} F_{s} \leq 1$. As proposed by Gabaix [18], we use a simplified variant of the attention rule in our simulation: $F_{s}=m_{F} \times F$ and $p_{s}=m_{p} \times p$. Under those assumptions, we obtain the condition $m_{p} \times p \times m_{F} \times F=m^{2} p F \leq 1$ if $m_{p}=m_{F}$. We utilize the last condition in order to compute the range of upper limits for the fine $F$ (Table 1). Second, we compute the lower bounds of attention to the fine schemes by $m_{F}^{*}>\frac{1}{F}$.

Table 1. Bounds for tax evasion under information inattention.

\begin{tabular}{ccccc}
\hline Detection & \multicolumn{2}{c}{ Upper Bounds for $\boldsymbol{F}$} & \multicolumn{2}{c}{ Lower Bounds for $\boldsymbol{m}_{\boldsymbol{F}}^{*}$} \\
Prob. & $\boldsymbol{m}=\mathbf{0 . 0 6}$ & $\boldsymbol{m}=\mathbf{0 . 3 5}$ & $\boldsymbol{m}=\mathbf{0 . 0 6}$ & $\boldsymbol{m}=\mathbf{0 . 3 5}$ \\
\hline$p=0.1$ & 166.667 & 28.571 & 0.006 & 0.035 \\
$p=0.3$ & 83.333 & 14.285 & 0.012 & 0.070 \\
$p=0.3$ & 55.556 & 9.523 & 0.018 & 0.105 \\
$p=0.4$ & 41.667 & 7.142 & 0.024 & 0.140 \\
$p=0.5$ & 33.333 & 5.714 & 0.030 & 0.175 \\
$p=0.6$ & 27.778 & 4.761 & 0.036 & 0.210 \\
$p=0.7$ & 23.809 & 4.081 & 0.042 & 0.245 \\
$p=0.8$ & 20.833 & 3.571 & 0.048 & 0.280 \\
$p=0.9$ & 18.518 & 3.174 & 0.054 & 0.315 \\
$p=1.0$ & 16.667 & 2.857 & 0.060 & 0.350 \\
\hline MAX-MIN & 150.000 & 25.714 & 0.054 & 0.315 \\
Mean & 48.816 & 8.368 & 0.021 & 0.119 \\
\hline
\end{tabular}

Table 1 represents the bounds for the fine scheme and the attention parameters. The thresholds for the fine $F$, denoted in columns two and three, are contingent on the detection probability and attention to the fine. In columns four and five, we see the lower bounds of attention so as to alleviate tax evasion across the range of detection probabilities. In case of low inattention (e.g., $m=0.06$ ), we need a rather high fine and/or detection probability in order to avoid tax evasion. This confirms our tax-inattention trade-off in Proposition 1. In addition, we obtain an estimate for the mean detection probability in order to prevent evading taxes. We find that the mean attention is of $\overline{m_{F}}=0.021$ under the lower inattention scenario (Table 1). If we use this mean as a benchmark, then the detection probability should be at least 40 percent given by $m^{*} \geq 0.024>0.021$ (Proposition 1 ). This level of the detection probability would guarantee on average a deterrent effect to tax evasion.

Finally, we compute the tax penalty in dollars for an evaded tax of $\$ 1000$. We distinguish the cases of full attention $\left(m_{t}=1.0\right)$ and inattention $\left(m_{t}=0.06\right.$ and $\left.m_{t}=0.35\right)$. The results in Table 2 demonstrate that the lower the detection probability, the higher the fine must be. However, if agents are inattentive about the true tax rate of 30 percent, i.e., they believe the tax rate is of $t_{s}=m_{t} \times t$ as suggested by Gabaix [18], then public policy must account for the subjective rate. Hence, under inattention, we obtain significantly lower fine boundaries (Table 2). Consequently, the minimum fine rate of 18 percent, which equals 
$\$ 180$, is sufficient to mitigate tax evasion under inattention, given a detection probability of 10 percent.

Our theoretical and numerical results unravel a better understanding of tax evasion under information inattention. Moreover, we find that tax evasion is contingent on the attention-magnitude of both the fine scheme and detection probability. Thus far, the literature induces a low attention to taxes [18]. A low mean attention, however, implies increasing tax evasion. However, there is little consensus about the estimates of attention [46]. Hence, our approach underscores an enormous need for empirical work on the notion of (in)attention to help guide public policy.

Table 2. Penalties for $\$ 1000$ evaded tax (in Dollars).

\begin{tabular}{cccc}
\hline Detection & Attention & \multicolumn{2}{c}{ Inattention } \\
Prob. & $\boldsymbol{m}_{\boldsymbol{t}}=\mathbf{1 . 0}$ & $\boldsymbol{m}_{\boldsymbol{t}}=\mathbf{0 . 0 6}$ & $\boldsymbol{m}_{\boldsymbol{t}}=\mathbf{0 . 3 5}$ \\
\hline$p=0.1$ & 3000.00 & 180.00 & 1050.00 \\
$p=0.3$ & 1500.00 & 90.00 & 525.00 \\
$p=0.3$ & 1000.00 & 60.00 & 350.00 \\
$p=0.4$ & 750.00 & 45.00 & 262.50 \\
$p=0.5$ & 600.00 & 36.00 & 210.00 \\
$p=0.6$ & 500.00 & 30.00 & 175.00 \\
$p=0.7$ & 428.57 & 25.71 & 150.00 \\
$p=0.8$ & 375.00 & 22.50 & 131.25 \\
$p=0.9$ & 333.33 & 20.00 & 116.67 \\
$p=1.0$ & 300.00 & 18.00 & 105.00 \\
\hline
\end{tabular}

Note: evaded tax $\$ 1000$ and tax rate $t=0.3$.

Overall, it can be inferred that the attention parameters on the tax rate, the fine scheme, the income, and the probability are major determinants to the level of tax evasion. All reaction functions to the attention parameters follow our expectations. Interestingly, Farhi and Gabaix [8] find that the Ramsey rule under information inattention suggests to increase taxes on inelastic goods and on goods with low attention. Thus, inattention implies higher optimal tax rates, which subsequently aggravate tax evasion. Consequently, information inattention might create a twofold amplification: on the one hand, higher optimal taxes on inattentive goods; on the other hand, negligible reaction on declared income in case of inattentive goods. Both effects cause tax evasion.

\section{Conclusions}

This paper advances the theory of tax evasion by introducing information inattention in the Allingham and Sandmo [12] model. This approach unravels insights for alleviating tax evasion more sustainably. We find that the attention parameters are of the same importance to mitigate tax evasion as the detection probability and the fine scheme. In general, the model develops a better understating of the channels through which public policies can leverage tax revenues. Based on our findings, one policy conclusion is that public authorities have to reconsider the agents' attention to the tax scheme as a whole. Perhaps this underpins the demand for more sustainable, transparent and simple tax rules, which might enhance individual's attention and thus helps mitigating attention-based tax evasion.

Funding: This research received no external funding.

Institutional Review Board Statement: Not applicable.

Informed Consent Statement: Not applicable.

Data Availability Statement: Simulation data is generic and the method is fully accessible and explained in the article. 
Acknowledgments: I would like to thank all conference participants and my research assistant Adrián Elsässer Briones for commenting a preliminary version of this paper. I thank the anonymous referees for valuable comments. All remaining errors are my own responsibility.

Conflicts of Interest: The author declares no conflict of interest.

\section{Appendix A}

Proof of Proposition 2. The straightforward differentiation of Equation (6) with respect to $p$ and $X$ gives

$$
\left[U^{\prime}(Y)+U^{\prime}(Z)\left[F_{S}-1\right]\right] d p_{s}+S d X=0 .
$$

Rearranging yields

$$
\frac{d X}{d p_{S}}=-\frac{\left[U^{\prime}(Y)+U^{\prime}(Z)\left[F_{S}-1\right]\right]}{S}
$$

which gives a negative fraction because per definition $F_{S}>1$ and $U^{\prime}(Y), U^{\prime}(Z)>0$ and $S<0$.

\section{Appendix B}

Proof of Proposition 4. The straightforward differentiation of Equation (6) with respect to $m_{F}$ and $X$ yields

$$
\left[p_{s}\left(F-F_{d}\right) U^{\prime}(Z)-U^{\prime \prime}(Z) p_{s}\left(F-F_{d}\right) t_{s}\left(M_{S}-X\right)\left[F_{S}-1\right]\right] d m_{F}+S d X=0 .
$$

Rearranging yields the condition in the proposition.

Proof of Proposition 5. The straightforward differentiation of Equation (6) with respect to $F$ and $X$ yields

$$
\left[p_{s} m_{F} U^{\prime}(Z)-U^{\prime \prime}(Z) p_{S} m_{F} t_{S}\left(M_{S}-X\right)\left[F_{S}-1\right]\right] d F+S d X=0
$$

Rearranging yields the condition in the proposition.

\section{Appendix C}

Proof of Proposition 6. The straightforward differentiation of Equation (6) with respect to $t$ and $X$ yields

$$
\left[-\left(1-p_{s}\right) U^{\prime \prime}(Y)\left(-m_{t} X\right)+p_{s} U^{\prime \prime}(Z)\left(F_{s}-1\right)\left(-m_{t} X-F_{s} m_{t}\left[M_{s}-X\right]\right)\right] d t+S d X=0 .
$$

The $d t$-term is rearranged, while utilizing the definition of the absolute risk aversion $R_{A}=-U^{\prime \prime}(Y) / U^{\prime}(Y)$ and the first-order condition $\left(1-p_{S}\right) U^{\prime}(Y)=p_{S}\left[F_{S}-1\right] U^{\prime}(Z)$, such that

$$
\begin{aligned}
&-\left(1-p_{s}\right) U^{\prime \prime}(Y)\left(-m_{t} X\right)+p_{s} U^{\prime \prime}(Z)\left(F_{s}-1\right)\left(-m_{t} X-F_{s} m_{t}\left[M_{s}-X\right]\right)= \\
&\left(1-p_{s}\right) U^{\prime \prime}(Y)\left(m_{t} X\right)-p_{s} U^{\prime \prime}(Z)\left(F_{s}-1\right) m_{t} X-p_{s} U^{\prime \prime}(Z)\left(F_{s}-1\right) F_{s} m_{t}\left[M_{S}-X\right]= \\
&\left(1-p_{s}\right) U^{\prime}(Y)\left[\frac{U^{\prime \prime}(Y)\left(m_{t} X\right)}{U^{\prime}(Y)}-\frac{p_{s} U^{\prime \prime}(Z)\left(F_{s}-1\right) m_{t} X}{p_{s}\left[F_{S}-1\right] U^{\prime}(Z)}-\frac{p_{s} U^{\prime \prime}(Z)\left(F_{s}-1\right) F_{s} m_{t}\left[M_{s}-X\right]}{p_{s}\left[F_{S}-1\right] U^{\prime}(Z)}\right]= \\
&\left(1-p_{s}\right) U^{\prime}(Y)\left[m_{t} X\left(R_{A}(Y)-R_{A}(Z)\right)-F_{s} m_{t}\left[M_{s}-X\right] R_{A}(Z)\right] .
\end{aligned}
$$

Hence, we obtain

$$
\left[\left(1-p_{s}\right) U^{\prime}(Y)\left[m_{t} X\left(R_{A}(Y)-R_{A}(Z)\right)-F_{s} m_{t}\left[M_{S}-X\right] R_{A}(Z)\right]\right] d t+S d X=0 .
$$

Rearranging gives the condition in the proposition. The same calculation follows for the other derivations. 


\section{Appendix D}

Proof of Proposition 7. The straightforward differentiation of Equation (6) with respect to $M$ and $X$ yields

$$
\left[-\left(1-p_{s}\right) U^{\prime \prime}(Y) m_{M}+p_{s}\left(F_{s}-1\right) U^{\prime \prime}(Z)\left(m_{M}-F_{s} T_{s} m_{M}\right)\right] d M+S d X=0 .
$$

The $d M$ - term is rearranged, while using the definition of the absolute risk aversion $R_{A}=-U^{\prime \prime}(Y) / U^{\prime}(Y)$ and the first-order condition $\left(1-p_{s}\right) U^{\prime}(Y)=p_{s}\left[F_{S}-1\right] U^{\prime}(Z)$, such that

$$
\begin{array}{r}
-\left(1-p_{s}\right) U^{\prime \prime}(Y) m_{M}+p_{s}\left(F_{s}-1\right) U^{\prime \prime}(Z) m_{M}\left(1-F_{s} t_{s}\right)= \\
-m_{M}\left(1-p_{s}\right) U^{\prime}(Y)\left[\frac{U^{\prime \prime}(Y)}{U^{\prime}(Y)}-\frac{p_{s}\left(F_{s}-1\right) U^{\prime \prime}(Z)\left(1-F_{s} t_{s}\right)}{p_{s} U^{\prime}(Z)\left(F_{s}-1\right)}\right]= \\
-m_{M}\left(1-p_{s}\right) U^{\prime}(Y)\left[-R_{A}(Y)+R_{A}(Z)\left(1-F_{s} t_{s}\right)\right]= \\
-m_{M}\left(1-p_{s}\right) U^{\prime}(Y)\left[\left[R_{A}(Z)-R_{A}(Y)\right]-F_{s} t_{s} R_{A}(Z)\right] .
\end{array}
$$

Furthermore, $S=\left(1-p_{S}\right) U^{\prime \prime}(Y)+p_{S} U^{\prime \prime}(Z)\left(F_{S}-1\right)^{2}$ can be rewritten as $\left(1-p_{S}\right) U^{\prime}(Y)$ $\left[\left[R_{A}(Z)-R_{A}(Y)\right]-F_{S} R_{A}(Z)\right]$. Hence, we obtain

$$
\begin{aligned}
& {\left[\left[-m_{M}\left(1-p_{s}\right) U^{\prime}(Y)\left[\left[R_{A}(Z)-R_{A}(Y)\right]-F_{s} t_{s} R_{A}(Z)\right)\right]\right] d M+} \\
& {\left[\left(1-p_{s}\right) U^{\prime}(Y)\left[\left[R_{A}(Z)-R_{A}(Y)\right]-F_{s} R_{A}(Z)\right]\right] d X=0 .}
\end{aligned}
$$

After rearranging, we obtain the condition in the proposition.

\section{Appendix E}

Proof of Proposition 9. The straightforward differentiation of Equation (6) with respect to $m_{M}$ and $X$ yields

$$
\left[-\left(1-p_{s}\right) U^{\prime \prime}(Y)(M-\bar{M})+p_{s} U^{\prime \prime}(Z)\left(F_{S}-1\right)\left[(M-\bar{M})-F_{s} t_{s}(M-\bar{M})\right]\right] d m_{M}+S d X=0 .
$$

The $d m_{M}$-term is rearranged, while utilizing the definition of the absolute risk aversion $R_{A}=-U^{\prime \prime}(Y) / U^{\prime}(Y)$ and the first-order condition $\left(1-p_{s}\right) U^{\prime}(Y)=p_{s}\left[F_{s}-1\right] U^{\prime}(Z)$, such that

$$
\begin{array}{r}
-\left(1-p_{s}\right) U^{\prime \prime}(Y)(M-\bar{M})+p_{s} U^{\prime \prime}(Z)\left(F_{s}-1\right)(M-\bar{M})\left[1-F_{s} t_{s}\right] \\
-\left(1-p_{s}\right) U^{\prime}(Y)(M-\bar{M})\left[\left[R_{A}(Z)-R_{A}(Y)\right]-F_{s} t_{s} R_{A}(Z)\right] .
\end{array}
$$

Again utilizing and rewriting the second derivative as $\left(1-p_{s}\right) U^{\prime}(Y)\left[\left[R_{A}(Z)-R_{A}(Y)\right]-\right.$ $\left.F_{S} R_{A}(Z)\right]$, we finally obtain

$$
\begin{aligned}
& {\left[-\left(1-p_{s}\right) U^{\prime}(Y)(M-\bar{M})\left[\left[R_{A}(Z)-R_{A}(Y)\right]-F_{s} t_{s} R_{A}(Z)\right]\right] d M+} \\
& {\left[\left(1-p_{s}\right) U^{\prime}(Y)\left[\left[R_{A}(Z)-R_{A}(Y)\right]-F_{S} R_{A}(Z)\right]\right] d X=0 .}
\end{aligned}
$$

Rearranging yields the condition in the proposition. Next, by proof of contradiction, we assume the opposite and show that

$$
\begin{array}{r}
(M-\bar{M}) \frac{\left[R_{A}(Z)-R_{A}(Y)\right]-F_{s} t_{s} R_{A}(Z)}{\left[R_{A}(Z)-R_{A}(Y)\right]-F_{s} R_{A}(Z)}<1 \\
\underbrace{(M-\bar{M}-1)\left(R_{A}(Z)-R_{A}(Y)\right)}_{+}+\underbrace{F_{S} R_{A}(Z)\left(1-m_{t} t\right)}_{+}<0 !
\end{array}
$$

Hence, the assumption that the fraction is less than one is rejected. The opposite holds true as in the proposition. 


\section{Appendix F}

Proof of Proposition 10. The derivative of $R=t X+p_{s} F_{S} t\left(M_{S}-X\right)$ is:

$$
\begin{aligned}
\frac{d R}{d p_{s}} & =F_{s} t\left(M_{s}-X\right)+t\left(1-F_{s} p_{s}\right) \frac{\partial X}{\partial p_{s}}>0 \\
\frac{d R}{d F_{s}} & =p_{s} t\left(M_{s}-X\right)+t\left(1-F_{s} p_{s}\right) \frac{\partial X}{\partial F_{s}}>0 \\
\frac{d R}{d t} & =X+p_{s} F_{s}\left(M_{s}-X\right)+t\left(1-p_{s} F_{s}\right) \frac{\partial X}{\partial t}>0 \\
\frac{d R}{d M} & =p_{s} F_{s} t m_{M}>0 \\
\frac{d R}{d m_{F}} & =p_{s}\left(F-F_{d}\right) t\left(M_{s}-X\right)+t\left(1-p_{s} F_{s}\right) \frac{\partial X}{\partial m_{F}}>0 \\
\frac{d R}{d m_{t}} & =t\left(1-p_{s} F_{s}\right) \frac{\partial X}{\partial m_{t}}>0 \\
\frac{d R}{d m_{M}} & =p_{s} F_{s} t M+t\left(1-p_{s} F_{s}\right) \frac{\partial X}{\partial m_{M}}>0 .
\end{aligned}
$$

This concludes the proof.

\section{References}

1. Bohn, H. The sustainability of budget deficits in a stochastic economy. J. Money Credit. Bank. 1995, 27, 257-271. [CrossRef]

2. Bohn, H. The behavior of US public debt and deficits. Q. J. Econ. 1998, 113, 949-963. [CrossRef]

3. Bohn, H. The sustainability of fiscal policy in the United States. Sustain. Public Debt 2008, 1, 15-49.

4. Herzog, B. Anwendung des Nachhaltigkeitsansatzes von Bohn zur Etablierung eines Frühindikators in den öffentlichen Finanzen Beitrag zur aktuellen Debatte der Föderalismuskommission II. Credit. Cap. Mark. 2010, 43, 183-206. [CrossRef]

5. Ramos-Herrera, M.; Prats, M. Fiscal Sustainability in the European Countries: A Panel ARDL Approach and a Dynamic Panel Threshold Model. Sustainability 2020, 12, 8508.

6. Briceno, H.; Perote, J. Determinants of the Public Debt in the Eurozone and Its Sustainability Amid the Covid-19 Pandemic. Sustainability 2020, 12, 6456.

7. Mirrless, J.; Diamond, P. Optimal Taxation and Public Production II: Tax Rules. Am. Econ. Rev. 1971, 61, 261-278.

8. Farhi, E.; Gabaix, X. Optimal Taxation with Behavioral Agents. Am. Econ. Rev. 2020, 110, 298-336. [CrossRef]

9. Scholz, J.; Pinney, N. Duty Fear and Tax Compliance: The Heuristic Bias of Citizenship Behavior. Am. J. Political Sci. 1995, 39, 490-512.

10. United State Government Accountability Office. Tax Gap: Complexity and Taxpayer Compliance; Technical Report GAO-11-7471; United State Government Accountability Office: Washington, DC, USA, 2004.

11. Alm, J.; McClelland, G.; Schulze, W. Why Do People Pay Taxes? J. Public Econ. 1992, 48, 21-38.

12. Allingham, M.; Sandmo, A. Income tax evasion: A theoretical analysis. J. Public Econ. 1972, 1, 323-338. [CrossRef]

13. Luttmer, E.; Singhal, M. Tax Morale. J. Econ. Perspect. 2014, 28, 149-168. [CrossRef]

14. Doran, M. Tax Penalties and Tax Compliance. Harv. J. Legis. 2009, 46, 111-161.

15. Clotfelter, C. Tax Evasion and Tax Rates: An Analysis of Individual Returns. Rev. Econ. Stat. 1983, 65, 363-373. [CrossRef]

16. Alstadsæter, A.; Johannesen, N.; Zucman, G. Tax Evasion and Inequality. Am. Econ. Rev. 2019, 109, 2073-2103. [CrossRef]

17. Sims, C. Rational inattention: Beyond the linear-quadratic case. Am. Econ. Rev. 2006, 96, 158-163. [CrossRef]

18. Gabaix, X. Handbook of Behavioral Economics—Foundations and Applications 2; Elsevier: Amsterdam, The Netherlands, 2019; Volume 2, Chapter Behavioral INattention, pp. 261-343.

19. Rey, M. Estimating tax evasions: The example of the Italian General Sales Tax. Public Financ. 1965, 20, 366-392.

20. Gutmann, P. The subterranean economy. Financ. Anal. J. 1977, 26-28, 499-519. [CrossRef]

21. Feige, E. The UK's unobserved economy. J. Econ. Aff. 1981, 1, 205-213.

22. Peacock, A.; Shaw, G. Tax Evasion and Tax Revenue Loss. Public Financ. 1982, 37, 269-278.

23. Feige, E.; McGee, R. Sweden's Laffer curve: Taxation and the unobserved economy. Scand. J. Econ. 1983, 85, 499-519. [CrossRef]

24. Chetty, R.; Looney, A.; Kroft, K. Salience and taxation: Theory and evidence. Am. Econ. Rev. 2009, 99, 1145-1177.

25. Blackburn, K.; Bose, N.; Capasso, S. Tax evasion, the underground economy and financial development. J. Econ. Behav. Organ. 2012, 83, 243-253. [CrossRef]

26. Reimers, O. Tax Evasion and the Shadow Economy. CESifo 2014, 4, 61-62.

27. Cobham, A.; Jansky, P. Global distribution of revenue loss from corporate tax avoidance: Re-estimation and country results. J. Int. Dev. 2018, 30, 206-232. [CrossRef]

28. Yitzhaki, S. A note on Income tax evasion: A theoretical analysis. J. Public Econ. 1974, 3, 201-202. [CrossRef] 
29. Srinivasan, P. Tax evasion: A model. J. Public Econ. 1973, 2, 339-346. [CrossRef]

30. Snow, A.; Warren, R. Ambiguity about audit probability, tax compliance, and taxpayer welfare. Econ. Inq. 2007, 43, 865-871. [CrossRef]

31. Lawsky, S. Modeling Uncertainty in Tax Law. Stanf. Law Rev. 2013, 65, 241-278.

32. Tversky, A.; Kahneman, D. Judgment under Uncertainty: Heuristics and Biases. Science 1974, 185, 1124-1130. [CrossRef]

33. Kahneman, D. Maps of Bounded Rationality: Psychology for Behavioral Economics. Am. Econ. Rev. 2003, 93, 1449-1475. [CrossRef]

34. Thaler, R. Toward a Positive Theory of Consumer Choice. J. Econ. Behav. Organ. 1980, 1, 39-60.

35. Thaler, R.; Tversky, A.; Kahneman, D.; Schwartz, A. The effect of myopia and loss aversion on risk taking: An experimental test. Q. J. Econ. 1997, 112, 647-661. [CrossRef]

36. Luo, Y. Consumption Dynamics under Information Processing Constraints. Rev. Econ. Dyn. 2008, 11, 366-385. [CrossRef]

37. Tutino, A. Rationally Inattentive Consumption Choices. Rev. Econ. Dyn. 2013, 16, 421-439.

38. Woodford, M. Information-Constrained State-Dependent Pricing. J. Monet. Econ. 2009, 56, 100-124. [CrossRef]

39. Lorenzoni, G. A Theory of Demand Shocks. Am. Econ. Rev. 2009, 99, 2050-2084. [CrossRef]

40. Mackowiak, B.; Wiederholt, M. Optimal Sticky Prices under Rational Inattention. Am. Econ. Rev. 2009, 99, 769-803.

41. Mackowiak, B.; Wiederholt, M. Business Cycle Dynamics under Rational Inattention. Rev. Econ. Stud. 2015, 82, 1502-1532.

42. Angeletos, G.M.; La'O, J. Sentiments. Econometrica 2013, 81, 739-780.

43. Gabaix, X.; Laibson, D.; Moloche, G.; Weinberg, S. Costly information acquisition: Experimental analysis of a boundedly rational model. Am. Econ. Rev. 2006, 96, 1043-1068. [CrossRef]

44. Gabiax, X. A sparsity-based model of bounded rationality. Q. J. Econ. 2014, 129, 1661-1710. [CrossRef]

45. Herzog, B. Optimal policy under uncertainty and rational inattention. Res. Int. Bus. Finance 2019, 50, 444-449. [CrossRef]

46. Allcott, H.; Lockwood, B.; Taubinsky, D. Regressive Sin Taxes, with an Application to the Optimal Soda Tax. Q. J. Econ. 2019, 134, 1557-1626. [CrossRef]

47. Boylan, S. Who Benefits from Tax Rate Transparency? Evidence from the Laboratory. J. Am. Tax. Assoc. 2013, 35, 65-83. [CrossRef] 